\title{
Angular Relationship between Frankfort Horizontal Plane and Sella-Nasion Plane in Nepalese Orthodontic Patients: A Cephalometric Study
}

\author{
Dr Jamal Giri,' Dr Prabhat Ranjan Pokharel,,2 Dr Rajesh Gyawali3 \\ ${ }^{3}$ Asst Prof, ${ }^{2}$ Asso Prof, Dept of Orthodontics, \\ BP Koirala Institute of Health Sciences, Dharan, Nepal
}

Correspondence: Dr Jamal Giri; Email: nepalipilot@gmail.com

\section{ABSTRACT}

Introduction: The angle between Frankfort horizontal (FH) plane and Sella-Nasion (SN) plane is considered to be $7^{\circ}$. Various studies have shown that the FH-SN angulations could vary; which can affect cephalometric diagnosis.

Objective: To determine average FH-SN angle for a group of Nepalese orthodontic patients. The secondary objectives were to assess whether the FH-SN angle exhibits sexual dimorphism and to evaluate the FH-SN angle in different skeletal relationships.

Materials \& Method: Lateral cephalograms of 238 orthodontic patients were hand traced and the angle between the FH and SN plane was measured and recorded. The cephalograms were also classified as skeletal Class I, II or III cases using Wits appraisal.

Result: The average FH-SN angle was $6.71^{\circ} \pm 3.13^{\circ}$. FH-SN angle was greater in female samples compared to males. However, the difference was not statistically significant. Similarly, the ANOVA analysis revealed no significant difference between FH-SN angles in different skeletal relationships.

Conclusion: The average FH-SN angle for a group of Nepalese orthodontic patients was $6.71^{\circ} \pm 3.13^{\circ}$. There was no statistically significant difference in FH-SN angle between skeletal Class I, II and III relationships.

Keywords: Frankfort horizontal plane, lateral cephalometry, Sella-Nasion plane

\section{INTRODUCTION}

Cephalometric analysis has been a mainstay of orthodontic diagnosis using different reference planes drawn by various investigators. ${ }^{1,2}$ Two of these reference planes which have passed the test of time are Frankfort horizontal plane (FH) and Sella-Nasion plane ( $\mathrm{SN}$ plane). $\mathrm{FH}$ plane is constructed by joining the inferior most point in bony orbit called orbitale (Or) with the superior most point on external auditory meatus called porion (Po). SN plane is constructed by joining the mid-point of sella tursica (S) with nasion (N). Commonly used cepahlometric analyses utilize these two planes. ${ }^{3}$ Though all cephalometric planes show some variations, SN plane followed by FH plane have been found to be relatively stable. ${ }^{4}$ The angle between these two planes is considered to be $7^{\circ} .5-7$ Any variation in the $\mathrm{FH}-\mathrm{SN}$ angulation can affect the cephalometric diagnosis.8.9 However various studies have shown that the $\mathrm{FH}-\mathrm{SN}$ angulation is not always $7^{0} .{ }^{10,11}$ Hence, assessment of $\mathrm{FH}-\mathrm{SN}$ angle is imperative before drawing any cephalometric conclusion.
The primary objective of this study was to determine an average $\mathrm{FH}-\mathrm{SN}$ angle for a group of Nepalese orthodontic patients. The secondary objectives were to assess whether the FH-SN angle exhibits sexual dimorphism and to evaluate $\mathrm{FH}-\mathrm{SN}$ angle in different skeletal relationships.

\section{MATERIALS AND METHOD}

Two hundred and thirty-eight lateral cephalograms of patients undergoing orthodontic treatment were randomly retrieved from Department of Orthodontics, BP Koirala Institute of Health Sciences, Dharan, Nepal. The radiographs were taken between January 2013 and December 2015 by a single technician using same cephalometric machine. The study was conducted after obtaining ethical clearance from the institutional review board of BPKIHS. Radiographs with unclear landmarks and magnified image were excluded from the study.

The lateral cephalograms were hand traced on 0.003 inch matte acetate tracing paper using sharp $3 \mathrm{H}$ 


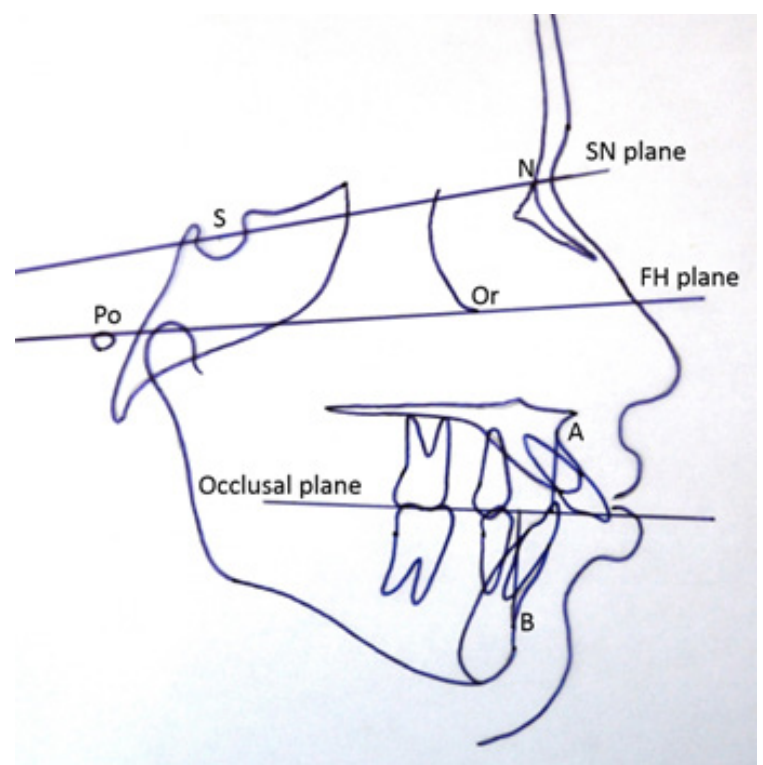

Figure 1: Landmarks used in study. Nasion (N), Sella (S), Porion (Po), Orbitale (Or), Point A (A), Point B (B), Sella-Nasion plane (SN plane), Frankfort horizontal plane (FH plane), Occlusal plane

drawing pencil by a single investigator (JG) to eliminate inter-examiner variability. Cephalometric landmarks were verified by another investigator (RG) before the reference planes (FH and SN) were constructed. The angle between the $\mathrm{FH}$ and $\mathrm{SN}$ plane was measured and recorded. Furthermore, a functional occlusal plane (line joining the overlapping cusps of first permanent molars and first premolars of maxillary and mandibular arch) was constructed on each tracing and perpendiculars were dropped from point $A$ and point $B$ on the occlusal plane (Figure 1). Then using the wits appraisal ${ }^{12}$ each lateral cephalogram was classified as skeletal Class I, II or III case. The method recommended by Houstan ${ }^{13}$ was followed to minimize errors during cephalometric analysis. After 2 weeks of initial measurement, 60 lateral cephalograms (25\% of the samples) were randomly selected and measured again to ensure the intra-observer variability.

Normal distribution of data was assessed using Kolmogorov-Smirnov and Shapiro Wilk tests. Mean and standard deviation of $\mathrm{FH}-\mathrm{SN}$ angle of the samples were calculated. Intraclass correlation coefficient (ICC) was calculated to assess the intraexaminer reliability. Relationship between the gender of the samples and $\mathrm{FH}-\mathrm{SN}$ angle was evaluated using independent samples t-test. One-way analysis of variance (ANOVA) was used for assessing the relationship between skeletal Class I, II and III malocclusion and FH-SN angle. SPSS software version 11.0 was used for data analysis.

\section{RESULT}

The average age of the samples was $19.19 \pm 6.12$ years. The values of Kolmogorov-Smirnov and Shapiro Wilk tests were above 0.05; which suggest the normal distribution of the data. The mean $\mathrm{FH}-\mathrm{SN}$ angle was $6.71^{\circ} \pm 3.13^{\circ}$. FH-SN angle was greater in female samples compared to males (Table 1); however, the difference was not statistically significant (Table 2).

Out of 238 samples; 117 had skeletal Class I relationship, 79 had skeletal Class II relationship and 42 had skeletal Class III relationship. When the mean FH-SN angles of 3 different skeletal relationships were compared using ANOVA analysis, it was found that that there was not statistically significant difference between the groups (Table 3). Intraclass correlation coefficient (ICC) demonstrated excellent intraexaminer reliability $(\mathrm{ICC}=0.91)$.

Table 1: Age and FH-SN angle of the samples

\begin{tabular}{|l|c|c|c|}
\hline \multicolumn{1}{|c|}{ Parameters } & Number of samples & Mean age (years) & Mean FH-SN angle (degrees) \\
\hline Male & 111 & $18.42 \pm 5.22$ & $6.36 \pm 2.76$ \\
\hline Female & 127 & $19.87 \pm 6.77$ & $7.01 \pm 3.4$ \\
\hline Total & 238 & $19.19 \pm 6.12$ & $6.71 \pm 3.13$ \\
\hline
\end{tabular}

Table 2: T-test statistics comparing FH-SN angle between gender groups

\begin{tabular}{|c|c|c|c|c|c|c|}
\hline \multirow{2}{*}{ Parameters } & \multicolumn{2}{|c|}{ Male } & \multicolumn{2}{|c|}{ Female } & \multirow{2}{*}{ t-Value } & \multirow{2}{*}{$p$-Value } \\
\hline & Mean & SD & Mean & SD & & \\
\hline FH-SN angle (degrees) & 6.36 & 2.76 & 7.01 & 3.4 & -1.624 & 0.106 (NS) \\
\hline
\end{tabular}

Table 3: ANOVA results comparing FH-SN angle between skeletal Class I, II and III

\begin{tabular}{|l|c|c|c|c|c|}
\hline \multicolumn{1}{|c|}{ Parameters } & Sum of Squares & df & Mean Square & F & p-Value \\
\hline Between Groups & 49.993 & 2 & 24.997 & & \multirow{2}{*}{2.578} \\
\hline Within Groups & 2278.542 & 235 & 9.696 & 0.078 (NS) \\
\hline Total & 2328.535 & 237 & - & & \\
\hline
\end{tabular}

NS: Not significant 


\section{DISCUSSION}

The present cephalometric study was conducted to determine an average $\mathrm{FH}-\mathrm{SN}$ angle for a group of Nepalese orthodontic patients. The average FH-SN angle was found to be $6.71^{\circ} \pm 3.13^{\circ}$. This value is near to the generally accepted $7^{\circ}$ angulation between $\mathrm{FH}$ and SN planes. But, there are studies which have reported $\mathrm{FH}-\mathrm{SN}$ angle greater than $7^{\circ}$ as well.7,10,11,14 This discrepancy in $\mathrm{FH}-\mathrm{SN}$ angle could be attributed to the racial variation that exist between the samples of those studies.

The mean $\mathrm{FH}-\mathrm{SN}$ angle of female samples of the present study was slightly greater than that of the male samples with $0.6^{\circ}$ greater on average. Huh et al ${ }^{14}$ had also reported similar finding. However, this difference was not found to be statistically significant. Moreover, any cephalometric difference less than $2^{\circ}$ is considered clinically insignificant. ${ }^{15}$ Hence, we can infer that the $\mathrm{FH}-\mathrm{SN}$ angle does not exhibit a significant statistical or clinical gender dimorphism.

Another objective of this study was to evaluate the FH$\mathrm{SN}$ angle in different skeletal relationships namely: Class I, II and III. The ANOVA analysis revealed that there was not a statistically significant difference between the FH$\mathrm{SN}$ angles in different skeletal relationships. This finding is not in agreement with Alves et $a^{16}$ who found that $\mathrm{FH}-\mathrm{SN}$ angle was greater in skeletal Class II relationship compared to skeletal Class III. A possible explanation for this discrepancy might be the difference in method used for classifying skeletal relationship. Alves et $a^{16}$ had used ANB angle for classifying skeletal relationship. Presence of landmark Nasion (N) in both ANB angle and $\mathrm{FH}-\mathrm{SN}$ angle could lead to confounding bias. Hence, it might be more prudent to use Wits appraisal to classify skeletal relationship, as done in this study because it eliminates the role of Nasion $(N)$ in classification of skeletal relationship.
It is evident that FH-SN angle displays inter-individual variability. Intra-individual variability of $\mathrm{FH}-\mathrm{SN}$ angle is still debated; though it is accepted that this angle remains nearly constant $\left(7^{\circ}\right)$ throughout an individual's life. There are studies which have reported an increase in FH-SN angle with age. ${ }^{7,14}$ The present study cannot answer this question whether the FH-SN angle changes with age because of its cross-sectional design. Hence, further longitudinal studies with adequate sample size are needed to assess the age-related changes in $\mathrm{FH}$ SN angle.

Variation in $\mathrm{FH}-\mathrm{SN}$ angle affects cephalometric diagnosis of an orthodontic case. According to Moore, 8 an increase in $\mathrm{FH}-\mathrm{SN}$ angle is associated with decrease in SNA and SNB values. Variation in FH-SN angle could be due to the change in inclination of SN line, $\mathrm{FH}$ line or both. Hence, it is imperative to evaluate the $\mathrm{FH}$ $\mathrm{SN}$ angle before making a cephalometric diagnosis. If the variation of $\mathrm{FH}-\mathrm{SN}$ angle is due to variation in $\mathrm{SN}$ line, cephalometric parameters which use $\mathrm{FH}$ line alone should be used for making cephalometric diagnosis; however cephalometric reference planes tend to be highly variable and poorly related. Hence, cephalometric analysis should be performed using more than one reference plane. ${ }^{17}$ Alternatively, perpendiculars to $\mathrm{FH}$ and $\mathrm{SN}$ lines could be used to reach the diagnosis. ${ }^{18}$

\section{CONCLUSION}

The average FH-SN angle for a group of Nepalese orthodontic patients was found to be $6.71^{\circ} \pm 3.13^{\circ}$. There was no statistically significant difference in FH-SN angle between skeletal Class I, II and III relationships. Similarly, gender dimorphism of FH-SN angle could not be established statistically. 


\section{REFERENCES}

1. Zebeib AM, Naini FB. Variability of the inclination of anatomic horizontal reference planes of the craniofacial complex in relation to the true horizontal line in orthognathic patients. Am J Orthod Dentofac Orthop. 2014; 146:740-7.

2. Nanda SK, Sassouni V. Planes of reference in roentgenographic cephalometry. Angle Orthod. 1965; 35:31 1-9.

3. Ricketts RM, Schulhof RJ, Bagha L. Orientation-sella-nasion or Frankfort horizontal. Am J Orthod. 1976; 69:648-54.

4. Wei SH. The variability of roentgenographic cephalometric lines of reference. Angle Orthod. 1968; 38:74-8.

5. Burstone CJ, James RB, Legan H, Murphy GA, Norton LA. Cephalometrics for orthognathic surgery. J Oral Surg. 1978; 36:269-77.

6. Mobarak KA, Espeland L, Krogstad O, Lyberg T. Soft tissue profile changes following mandibular advancement surgery: Predictability and long-term outcome. Am J Orthod Dentofac Orthop. 2001; 119:353-67.

7. Greiner P, Müller B, Dibbets J. The angle between the Frankfort horizontal and the sella-nasion line. Changes in porion and orbitale position during growth. J Orofac Orthop. 2004; 65:217-22.

8. Moore JW. Variation of the sella-nasion plane and its effect on SNA and SNB. J Oral Surg. 1976; 34:24-6.

9. Leitão P, Nanda RS. Relationship of natural head position to craniofacial morphology. Am J Orthod Dentofac Orthop. 2000 ; $117: 406-17$.

10. Alves PVM, Mazucheli J, Vogel CJ, Bolognese AM. A protocol for cranial base reference in cephalometric studies. J Craniofac Surg. 2008; 19:211-5.

11. Ellis E, McNamara J. Cephalometric reference planes sella nasion vs Frankfort horizontal. Int J Adult Orthod Orthognath Surg. $1988 ; 3: 81-7$.

12. Jacobson A. The "Wits" appraisal of jaw disharmony. Am J Orthod. 1975; 67:125-38.

13. Houston WJ. The analysis of errors in orthodontic measurements. Am J Orthod. 1983; 83:382-90.

14. Huh YJ, Huh KH, Kim HK, Nam SE, Song HY, Lee JH. Constancy of the angle between the Frankfort horizontal plane and the sella-nasion line: A nine-year longitudinal study. Angle Orthod. 2014; 84:286-91.

15. Damstra J, Huddleston Slater JJR, Fourie Z, Ren Y. Reliability and the smallest detectable differences of lateral cephalometric measurements. Am J Orthod Dentofac Orthop. 2010; 138:546.el-8.

16. Alves P V, Mazuchelli J, Patel PK, Bolognese AM. Cranial base angulation in Brazilian patients seeking orthodontic treatment. J Craniofac Surg. 2008; 19:334-8.

17. Madsen DP, Sampson WJ, Townsend GC. Craniofacial reference plane variation and natural head position. Eur J Orthod. 2008; 30:532-40.

18. Incisivo $\mathrm{V}$, Silvestri A. The reliability and variability of SN and PFH reference planes in cephalometric diagnosis and therapeutic planning of dentomaxillofacial malformations. J Craniofac Surg. 2000; 11:31-8. 